\title{
Chapter 9 \\ How Environmental Changes Result in Migration Aspirations and Other Adaptation Strategies of Moroccan Inhabitants and Migrants in Belgium
}

This book provides a unique approach to the Moroccan context. Many researchers have conducted fieldwork in Morocco, departing from migration studies (e.g., De Haas 2003, 2006, 2010; Czaika and De Haas 2011; De Haas and El Ghanjou 2000), while others solely focused on environmental and climate changes (e.g., Schilling et al. 2012), leaving the interplay between both to be explored more in-depth. The Moroccan context offers a unique research context because it is confronted with gradual environmental change over the last decades and has initiated considerable action at the national level to develop policies or strategies to counteract these changes. Hence, Morocco in 2019 ranked among the leading countries in the fight against climate change on the Climate Change Performance Index (Burck et al. 2019). Furthermore, Morocco evolved into one of the world's leading emigration countries in the second half of the twentieth century, being characterized by unexpected developments, including colonial migration, labour migration, family reunification, and, recently, undocumented migration. This led to a high degree of internal differentiation within the Moroccan migrant population and strong and influential migrant networks (De Haas 2007; Schilling et al. 2012; cf. Chap. 3).

Considering this particular Moroccan context and migration to Belgium together with previous insights from migration research, in Chap. 2 environmental migration is approached from existing and well-known migration theories to serve as a starting point to frame the empirical findings and guidance throughout the fieldwork. The chapter serves to reflect more on the ways in which ongoing migration dynamics itself interferes with changes in the natural living environment. These insights, as well as the first encounters throughout the fieldwork, already suggested that not all inhabitants in a specific region perceive and interpret environmental changes in a similar way, as later studied in Chaps. 5 and 8, and how this impacts the development of adaptation strategies, as examined in Chap. 6. The importance of the ongoing migration dynamics is mainly elaborated upon in Chap. 7, as analyses delve deeper into how environmental changes fuel migration aspirations and how this is embedded within the prevailing cultures of migration in Tinghir and Tangier. Finally, the importance of cultures of migration, migrant systems, and remittances 
for (environmental) migration is examined in Chap. 8, which studies how migrants coming from Morocco and currently living in Belgium re-interpret their migration trajectories, in retrospect, to reflect upon the environmental changes in their country of origin and discuss how remittances are sent and used by their families. The research design and methods applied in this book are part of the widerMIGRADAPT research project (cf. Chap. 4) and allow us to elaborate in depth on the perceptions of environmental change, linkages with migration, and other adaptation strategies of people involved. Attention could thus be given to meaning-making processes, responses, and explanations of people living in gradually degrading areas from an open perspective, without being guided by ongoing climate change discourses that prevail in Western societies and dominant institutions, such as the Intergovernmental Panel on Climate Change (cf. IPCC 2014).

In the fifth and sixth empirical chapters, belief systems of people living in Morocco are examined to understand how perceived environmental changes are being linked to migration aspirations or trajectories themselves. Although at a macro-level, this linkage seems to be made easily, this relationship is not so straightforward at the individual or community levels.

In Chap. 5, the main finding that forms the red threat for the rest of the empirical chapters is that people living in Tangier and Tinghir do not necessarily approach environmental changes from a purely scientific perspective (cf. Chap. 8). Furthermore, given the relatively large timespan for these changes to occur, especially in the gradually-degrading natural living environment of Morocco, environmental changes are not always so easy to perceive by individuals. This finding has far-reaching impacts on the study of environmental migration since this is a condition for categorizing migration aspirations and trajectories in terms of environmental migration or to conceive migration as an adaptation strategy, or both. The chapter investigates two main research questions, namely how people perceive and explain environmental changes in their immediate living environment. Perceptions of climate/environmental change depend on knowledge of scientific climate change discourses and human-nature relationships (Salmón 2000; Rigby 2016). Perceptions of environmental change vary across and between regions, which in most cases relates to the personal experiences people (and their networks) have with the consequences of environmental change for their daily activities and income.

Within regions, differences in the knowledge of climate change discourses are noted that depend on individuals' educational levels as well as their migrant networks (especially in Europe). The means for acquiring information about environmental changes in the immediate natural environment, as well as the knowledge of climate change discourses, seems to also play a crucial role in the extent to which people think these environmental changes are happening within their immediate environment, and how people explain such changes. More specifically, people who personally have seen environmental change or are confronted with its consequences seem to frame it more often in terms of natural cycles and laws, or refer to God, implying the adherence of ecocentric or theocentric human-nature relationships. This group of respondents consists especially of lower educated people. Respondents who are far more aware of 'statistical' climate change discourses do not 
necessarily relate these to the local Moroccan context or estimate the impact it can have on people's everyday lives.

These findings are in line with prevailing ideas on nature and religion, within both the Islam and Amazigh cultures (Hart 1999; Izzy Deen 2003; Ammar 2013; Karrouche 2017). More specifically, religious beliefs and views on nature are considered when studying the ways people look at and deal with environmental changes and issues, such as water and drought. Although there are many prescriptions on nature conservation in Islam, this relates to people's own behaviour regarding nature conservation, and not necessarily to feeling the adverse impact of gradually-degrading environmental changes in one's living environment and developing adaptation strategies to deal with those or to avoid risks related to environmental changes. Rather, these verses and overall attitude suggest that one should live in harmony with nature and respond accordingly. Hence, this does not automatically relate to statistical climate change discourses. This leads to the finding that different learning methods for acquiring information on environmental changes in Morocco through education or the media about more official and scientifically-approved climate change discourses versus the development of tacit knowledge and skills that are built up over the years when working in affected domains. This also means that not the entire population is aware of environmental change, and hence, merely sees the lack of employment opportunities, the relatively lower standard of living, and the search for better opportunities to improve one's lives and spread risks in the household.

In general, the findings of Chap. 5 show how human-environment interactions differ across the globe and how variation within regions are even bigger when facing rapid development, changes, and having large disparities in educational level, ranging from illiterate people to people who have attained higher education (abroad). Moreover, the ways in which people living in Morocco modify, symbolize, and adapt their immediate natural environment varies considerably, and especially, deviates from the dominant perspectives present in international conferences on climate change (cf. IPCC 2014) and treaties (cf. Paris Agreement, etc.). In line with recent trends in cultural and political ecology, the chapter demands the inclusion of power structures, discourses, and identities in ecological settings. In doing so, local communities and prevailing beliefs concerning environmental issues need to be considered in order to also incorporate the broader political and economic contexts in future research (Haenn and Wilk 2006).

Chapter 6's findings lead to a better understanding of how individual migration aspirations are developed, framed, and linked to the changing natural environment. An important finding that results from the data is that environmental change is not necessarily perceived as a risk that needs to be countered by actively developing adaptation strategies. Instead, environmental and societal changes together form the basis to seek ways of adapting to this changing situation as best as possible. While migration could be one potential adaptation strategy - and people aspire to migrate or have migrated before - environmental changes are not seen as sufficient reasons to (be willing to) move away from areas or relatively smaller towns such as Tinghir. Hence, migration aspirations and projects should be understood within the wider 
social, economic, political, and cultural contexts and is also perceived as such by the people involved. Analogous to the findings of Chap. 5, the explanation given to environmental changes and the knowledge of climate change discourses is a determining factor to understand how people deal with environmental change or develop individual/community/societal adaptation strategies. Furthermore, the use of particular adaptation strategies is very much limited by the available resources, abilities, and knowledge at the disposal of individuals and households. This is also reflected in the small number of community-wide projects or initiatives undertaken to counteract environmental change and its consequences. Resulting from this chapter, individual adaptation strategies are not necessarily in line with adaptation strategies developed at other levels of governance. This could contribute to the creation, or the further strengthening, of social inequalities when facing the consequences of environmental changes (Adger et al. 2009). Rather, these individual adaptation strategies are structured by constraint opportunities, expectations of environmental change and risks, and a mixture of perceived and expected desired future realities, and impacted by climate change discourses, previous experiences, and available resources. These results indicate the social embeddedness of migration aspirations and environmental changes and how they further reinforce existing social inequalities. The focus on this topic is important when shifting the perspective slightly from mitigation to adaptation, and from the macro- and meso- to the micro-level. When doing so, decisionmaking processes of people and strategy-making in a constrained environment needs to be taken into account (Zetter 2017).

Taking insights from both Chaps. 5 and 6 together, some general conclusions can be drawn on this topic of study. The discordance between global climate change discourses and perceived environmental changes in one's local and immediate contexts seems to hinder the creation of well-developed and informed adaptation strategies directed at environmental changes and are rather converted into survival strategies of individuals facing economic hardship. People who were aware of environmental change discourses are often unable to apply these abstract ideas into their own living environment (Adam 1998, 2005). This general difficulty of 'climate change discourses' - often placed in a faraway geographic region and categorized in futuristic terms and debates centred on and dependent upon future predictions (Adam 1998, 2005) - are even more pronounced in the studied regions in Morocco. The differences in educational attainment, literacy, and professional attainment to a large extent determine the level of knowledge on this matter and awareness of prevailing discourses on environmental change. These diverging discourses are rooted in the clustered differences in age (and hence capacity to observe environmental changes in one's own living environment), literarcy, and education level (and access to sources or knowledge of climate change discourses) and gendered roles in the household, social life, and division of labour. For instance, females are more inclined to work in the fields and experience environmental changes first-hand; males are more pressured to provide for their family or in administrative functions, or both. Furthermore, people's views on the human-nature relationships are a crucial element in the understanding of how migration aspirations and actual migration trajectories are developed and linked to environmental changes. 
The reasoning behind environmental migration is actually quite extended, which is visible through a wide variety of elements, all following up on each other and entangled with other contextual features. This complicates the perceived linkage between environmental changes and migration, especially in a gradually-changing natural environment like Morocco. As a precondition to linking these elements to each other, people must reflect upon a long chain of factors, at both micro and macro levels, that result in migration.

In Chaps. 7 and 8, the importance of migrant networks, dynamics, and cultures of migration are examined in greater depth. These chapters build further on migrant systems theory, migrant network theory, segmented/dual labour market theory, transnationalism, and new economics of labour migration (cf. Chap. 2). Following migrant network theory, extensive migration networks have been established since the second world war that have led to chain migration. Partly because of this, environmental migration motivations are often overshadowed by, or intertwined with, other factors that coincide with such environmental changes or are the consequence of such changes. Building further on this, migrant systems theory has posited that, after initial migration has taken place and communities have been built abroad, cumulative causation and contextual feedback results in the further continuation or hampering of migration. This is found to differ across Tangier and Tinghir, as well as within the municipality of Tinghir, due to differential socioeconomic positions and access to migrant networks. The current economic and political situation in different cities in Morocco (i.e., the vibrant and growing city of Tangier vs the graduallydegrading environment in Tinghir, in terms of agricultural innovation and environmentally, combined with an ageing population) have created large social inequalities within Morocco, with an increasing segmentation of the labour market, and different needs, abilities, and vulnerabilities with regard to employment. These employment circumstances of individuals and households further creates the need for migration and the ability to develop migration aspirations. For example, environmental changes -combined with the lack of investment in agriculture and migration opportunities and remittances - seem to lead to fewer employment opportunities in Tinghir. This particularly affects the younger generations, who are still willing and able to migrate, but who have also lost interest in 'outdated' agricultural activities in their immediate living environment. Finally, transnational ties and social and financial remittances do not automatically lead to the creation and development of suitable adaptation strategies, at the individual and community levels, to better deal with environmental change. The Moroccan government's efforts seem to apply to particular regions and state-level efforts, such as construction of dams or solar panel gardens, but does not visibly impact households or reduce the need to migrate. Households often respond to deteriorating environmental conditions and economic opportunities by diversifying risks in the household and developing 'intergenerational' migration aspirations. In casu, in affected households, both young and old wished that especially the young (males) would be able to migrate and create a better life elsewhere. While thinking of cross-border migration would mainly go beyond imagination, most households referred to moving to larger urban 
areas, such as Tangier or Casablanca, with (perceived) growing economic opportunities.

Chapter 7 examined the nexus between environmental changes, culture of migration, and migration aspirations. In the two emigration areas studied, distinct views on migration to Europe are widely shared. More specifically, the consequences of migration did not necessarily lead to the development of similar cultures of migration (Timmerman et al. 2014b). Morocco's migration history and consequent migration dynamics have resulted in the formation of more or less three distinct cultures of migration: one prevailing in more advantaged social milieus in Tangier, one shared by internal migrants in Tangier searching for better opportunities in Morocco or elsewhere, and one in Tinghir that especially emphasizes the positive consequences of migration for people with access to transnational social capital. These cultures of migration are shaped through (the lack of) cumulative causation of transnational social networks. The existing cultures of migration in Morocco, in this case in the regions of Tangier and Tinghir, especially demonstrate how widespread migration has formed future migration dynamics and reshaped social structures and organization in Morocco, even contributing to the widening of social, ethnic and gender inequalities. This also impacts people's vulnerabilities towards environmental change. Individual vulnerabilities to environmental changes differ across age, gender and educational level, professional experience and migrant networks. Especially in Tinghir, having access to transnational social capital (Portes et al. 2002; Eckstein 2010) seems to matter for the current shaping of vulnerabilities towards environmental changes in the immediate living environment. People with access to transnational networks also more easily access resources to diversify their income and reduce their vulnerabilities against environmental change. Respondents without transnational networks are more vulnerable to the consequences of environmental changes as they still rely on the subsistence economy for survival or to complement their family income, and are at the same time unable to migrate to other regions or countries. Consequently, through the remittances sent, migrant networks decrease individuals' vulnerabilities to environmental change, albeit not at the societal and community levels.

Finally, in Chap. 8, Elodie Hut and Caroline Zickgraf examined the relationship between migrants' perceptions of environmental changes, the causality of migration, and subsequent transnational practices' impacts on environmental resilience and adaptive capacity in communities of origin by focusing on the Moroccan diaspora in Belgium. This chapter offers insights on the multi-causal nature of migration journeys and other structural elements that come into play in the Belgo-Moroccan context, such as pre-existing migration networks, historical migration trends, and cultures of migration. Furthermore, the chapter tests the concept of 'migration-asadaptation' and appraises its relevance within the field of environmental migration. The chapter's results stress the limited and relative (perceived) importance of environmental factors compared to other social, economic, demographic, and political drivers of human mobility. Interestingly, within this sample of Moroccans who had migrated to Belgium, socio-economic and especially family-related reasons appeared as the main factors that initiated the development of migration aspirations 
and plans - despite the impact people in Morocco feel from slow and gradual environmental changes, such as drought, especially the irregular and erratic rainfall that makes them aware of these changes. As also suggested in earlier chapters, people who migrated are not necessarily those who were most heavily impacted by these environmental changes for their personal living. The impact of environmental changes should be seen as seeming to be different across social classes and professions, and thus often related to education levels as well. The findings of Chap. 8 highlight how 'migration-as-adaptation' could be used within this context and should be considered within the structural context of the Belgo-Moroccan context.

To conclude, both Chaps. 7 and 8 demonstrate that environmental migration should not be studied in a social vacuum but should be approached from a migration perspective as well. Focusing too closely on migration as an adaptation strategy for dealing with environmental change may sometimes be misleading and fail to grasp how migration trajectories take shape. Additionally, by consolidating insights from Moroccans living in Morocco and Belgium, the empirical findings seem to align with each other. The combination of both migration contexts suggests that in many cases migration aspirations and trajectories should be understood within the broader social, economic, and political contexts. Both those who have already migrated and those who have not but aspire to (themselves or future generations) consider their own socio-economic situation and the ability to migrate (cf. Carling and Schewel 2018; Zickgraf 2018). Furthermore, there also appears to be a mismatch between those who are more able to migrate and those who are most heavily affected by environmental changes for their family survival. This is an important finding since it means that the people most vulnerable to the impacts of environmental changes, within this specific context, are also those who are often not able to aspire to or imagine migrating. In a context of slow-onset environmental changes, this seems to result in the creation of 'trapped populations', which can then be interpreted as vulnerable groups, heavily affected by environmental changes, who are in general too poor to migrate themselves. Adding more insights from migration theories, it is not surprising that especially the most-affected people are those most vulnerable in society, i.e., females, elderly, and those from lower socio-economic classes or working in agriculture. Migration visions are thus reserved for future generations or directed towards less favourable destinations (within Morocco or less industrialised countries) to work in difficult labour conditions and be less able to use their migration as an adaptation strategy to deal with environmental change. Rather, their migration trajectory will mainly be undertaken for individual survival and less to structurally contribute to ways in which the migrant and their family will be able to shield against even worse environmental conditions or counteract disruptive effects of environmental changes. 


\subsection{Useful Insights for Policymakers}

Concerning perceptions of environmental change, a multitude of perceptions exist and need to be taken into account when designing environmental and migration policies. This is an especially useful finding with regard to international policymaking and panels on environment-related issues. Overlooking people's visions on nature and the position of humans in this vision, the social, cultural, and religious embeddedness of discourses related to the environment, nature, and destiny, and finally people's explanations of environmental change may cause a mismatch in the developed policies and instruments to mitigate and adapt to climate/ environmental changes, resulting in policies that miss their target. In line with this and in order to apply adaptation strategies in a successful way in regions highly affected by environmental change, inhabitants need to be sensitized about environmental changes before being able to actively set out adaptation strategies at the individual and community levels. In doing so, attention should be given to how generic climate change discourses are applied to the local context. Furthermore, it is important to note that policymakers cannot expect a shift in people's views on environmental changes nor should they force this. Therefore, dialogue on environmental issues is necessary before co-creating adaptation strategies between policymakers and community members to deal with environmental change that also fit everyday reality, local cultures and views, and informs individual and policy decision-making. Finally, policymakers could pay attention to how ongoing discourses on environmental change are used and help individuals, households, associations, and local communities to make informed decisions about the adaptation strategies people will use and allow the development of long-term strategies.

With regard to the development of adaptation strategies to deal with environmental change, more coordinated action is necessary and evaluation research on these actions is highly needed. This could take place at the level of organisations grouping together both resources and knowledge to counteract the disruptive effects of environmental changes in people's living environment. As stated above, these actions need to consider the diversity of explanations and views on environmental change. Additionally, policymakers should develop policies that reduce vulnerabilities towards environmental change, assist (or even fund) organisations when designing their policies, or play a redistributive role in the resources gained from migration. Finally, policymakers could group together knowledge on all available adaptation strategies for people living in a particular region to facilitate the dissemination of knowledge on how to deal with environmental change in a specific setting. The role migration could play in the development of these adaptation strategies, or as an adaptation strategy itself, however, is not so straightforward.

With respect to the migration context and local cultures of migration, it often seems hard (and undesirable) for policymakers to counteract ongoing migration dynamics and the sending of remittances to families and communities of origin that may interfere with environmental or even developmental policies. Policymakers could, however, rethink existing migration policies or application procedures for 
migrants that are restricted to the individual level and do not consider the overall impact of environmental changes on the wider environment or consider families and different generations as a whole. People's adaptation strategies towards environmental changes and their inability to migrate are clearly embedded within larger socio-economic and political structures (cf. Schilling et al. 2012) and legal frameworks, and driven by the prevailing culture of migration and networks. Hence, this complicates the development of adaptation strategies of individuals, households, and even communities when facing environmental changes. Therefore, the development of adaptation strategies should be multi-tiered and start at the governmental level. The combination of a coordinated policy with different policy levels is necessary as environmental adaptation is seen in international policies as something to be organized at the local or regional level, whereas this is not necessarily the case for migration (IPCC 2014). The collective grouping or organizing of adaptation strategies seems to be insufficient to reach those groups who are most vulnerable, and furthermore do not consider the differentiated vulnerabilities of males and females. Therefore, a differentiated approach towards adaptation strategies within communities needs to be applied that helps identify a more precise evaluation of the needs and vulnerabilities of the local population when reducing environmental change impacts and helps map out the barriers towards a successful implementation of developed adaptation strategies (Biesbroek et al. 2013). This differentiated approach could reduce the unequal vulnerabilities regarding environmental change, which continues to give rise to migration aspirations. This also requires the investment in education for all and equal access to collective goods and resources, a redistribution of money and resources, defragmentation of lands, and investment in the introduction of modern technologies in agriculture. In short, this will require more redistributive societal changes. When looking at the role migration could play as an adaptation strategy for dealing with environmental change, future policy initiatives could canalize how migration could contribute to structural investments in the region of origin that even prevents migration and maladaptation to environmental change (cf. Lobell et al. 2013; Khachani 2009; Nyberg Sørensen 2004).

For diaspora communities across Europe and elsewhere, policymakers could assist local migrant communities to reflect on the ongoing larger and structural difficulties people living in their region of origin face. As most migrants mainly contribute to the overall survival of the people within their networks, remittances are often insufficient in helping deal with disruptive environmental changes. Furthermore, given the fact that remittances often contribute to creating of social inequalities within communities in Morocco, their social networks are often not those most-heavily affected by these environmental changes. Rather, because of the remittances they receive, they are able to move away from businesses or occupations with a higher risk to adverse impacts of environmental change and suffer less from environmental change in their daily lives. Policymakers, non-governmental organisations, and initiative-takers could help migrant communities reorient remittance practices into actual and successful adaptation strategies for dealing with environmental change. 
When translating these findings into the legal and policy debates that evoke the study of environmental migration, the question that needs to be asked is: 'how can the findings of this book contribute to the development of a new category to secure the protection of environmental migrants and displaced persons?' (Havard 2007). While the main insights in these debates are that they further challenge the existing difficult categorization of migrants and refugees according to their 'migration motivation' - i.e., as being economic, political, humanitarian, or family-related. Crawley and Skleparis (2017) refer to this as 'categorical fetishism', which is even more visible when attempting to develop new migrant categories. As many migration reasons overlap and interact - which is certainly the case for environmental factors - the categorization of movements based on their migration motivation is additionally challenged and seems hard to maintain in the future. This is especially so for environmental migrants. Policy decisions will have to be made about who exactly falls under the category 'environmental migrant/refugee' and at which policy level this needs to be done (e.g., European, local, national, global). When drafting this category, attention must be paid to internal migration processes (McLeman and Gemenne 2018), immobile vulnerable groups unable to migrate themselves (Zickgraf 2018), the self-categorization of environmental migrants (cf. Chaps. 5 and 6), and the specific time dimension of environmental changes and migration processes (Beck 1992; Wodon and Liverani 2014; Collyer 2010). Even when all these elements are perfectly defined, it remains a difficult and complex task to determine how environmental migrants or refugees can be recognized and which immigration country/region needs to host this group. An additional challenge for the categorization of environmental migrants relates to how the impact of environmental changes, especially gradually-occurring, can be demonstrated (Havard 2007). Finally, when creating such a category of environmental migrants and the protection and hosting of this group, there is an additional ethical question that will be hard to respond to (in this book), namely: 'In developing these policies, should policymakers consider prior social, historical debts and responsibilities related to the emission of greenhouse gases?' The creation of a new category of 'environmental migrants' and the debates surrounding this issue show that the existing legal migration frameworks are increasingly being challenged. Creating an appropriate policy requires political courage, international cooperation, and an integrated regional policy on climate adaptation.

This book's findings suggest that, when considering the actual nature of environmental migration patterns and trajectories, more regional approaches could yield further interesting results. This way, policymakers could consider the very regional environmental changes and impacts, as well as the migration dynamics, within a particular broader social, political, and economic context. Hence, building on these insights, it would be necessary to develop a clearer legal framework and possibly create a new category, indicating when someone from a certain region can appeal to this framework in cooperation with the country/region of origin. Analogue to the category of 'internally displaced persons', a category of 'environmentally displaced persons' could be developed. When doing so, policymakers should learn from the difficulties in the development of a policy framework for the protection of 'internally 
displaced persons'. For instance, the implementation challenges of the AU Kampala Convention show that one should not only look at these conventions, but also provide support for their successful implementation (cf. AU 2009). Building further on these insights, it is necessary to develop a binding legal framework around this concept (UNHCR 2018; Stavropoulou 2008; Havard, 2007; Biermann and Boas 2008). An alternative option is to consider the role of the natural environment and changes in it when developing international and generic migration agreements, such as the UN Global Compact for Safe, Orderly and Regular Migration (GCM) (UN 2018). Or, to develop a regional approach to environmental migration and displacement (UNHCR 2018; Stavropoulou 2008; Havard 2007). As the findings of this book illustrate, in Morocco, many small-scale initiatives, grassroots activities, and associations were set up that are highly dependent on remittances and the input of migrant networks. Therefore, a third option is to develop a new international framework that, for example, does not touch upon the Geneva Convention but focuses specifically on environmental migrants and displaced persons living in a particular region.

Biermann and Boas $(2008,2017)$ expect that future technological developments will enable us to better assess the risks for people living in a specific region and which can help to implement a more targetted regional plan. In their plea for a separate legal framework, five principles must be maintained in order to provide adequate protection for climate migrants - and to also be successful. First, this agreement must focus on the planned and voluntary resettlement and reintegration of the persons concerned over many years and decades (i.e., no emergency solution). Second, unlike some political refugees, this new framework should involve the permanent migration of environmental migrants in the migration regions. Third, such regimes should not be adjusted to individuals but to entire groups, such as the inhabitants of certain villages, cities, regions, or even countries, such as the people living in the Kiribati Islands - also known as the first 'climate refugees' (Farbotko and Lazrus 2012; McNamara and Gibson 2009). Fourth, governments and local communities must also be supported in organizing and financing the protection and resettlement of environmental migrants, when they request it. Finally, the protection of climate refugees must be seen as a global responsibility, especially since most environmental migrants are very poor and have also made little contribution to the emission of greenhouse gases. The authors hereby refer to an 'international list of populations concerned', provided by countries and regions themselves and supported by an international committee. Havard (2007) also refers to the potential of regional agreements, such as regional treaties that extend the Refugee Convention further to include specific refugee problems in Africa. Even if the policy on environmental migration and displacement is part of an integrated climate adaptation plan, regional definitions, partnerships, and policies can offer advantages (see UNDP 2018). This regional approach can allow policymakers to evaluate environmental migration alongside other adaptation strategies to deal with environmental changes. Furthermore, the use of an integrated approach would help to place climate migration in a broader social, political, and economic context, and thus better assess the effects and processes of environmental migration (UNDP 2018). In other words, a 
more differentiated and regional approach, with an international framework and support, could offer a way out for the better protection of a 'difficult to categorize' group. Finally, given the specific relationships between environmental changes and migration, one can also protect a specific target group. An example cited by Morel and De Moor (2012) in the context of international migration law, are migrant workers who, voluntarily or not, have to migrate due to the adverse effects of environmental change whose movement can be made easier through bilateral and multilateral agreements to migrate. This way, the differential impact of environmental changes on the population and regions can be better taken into account, which could be an asset.

\subsection{Future Research Recommendations}

Based on insights gained in the making of this IMISCOE Springer book, some recommendations can be made for further research.

For starters, in book's first part presents a theoretical framework to better focus on the ways people adapt to their changing natural living environment and how this might lead to migration aspirations and actual migration trajectories. The emphasis on the development of migration aspirations and how this could lead to potential migration trajectories is of particular interest for the body of research on environmental migration for four reasons. First, the focus on migration aspirations helps to grasp the gradual development of migration decision-making processes. Second, examining migration aspirations helps to provide a better understanding of how selfcategorization processes of environmental migrants could work. Third, migration aspirations reflect the social fabric that shapes environmental discourses, perceptions about environmental changes, and migration dynamics. Finally, when studying migration aspirations first, instead of solely focusing on migration outcomes, one can also involve immobile groups who are unable or unwilling to migrate, as well as environmentally (internally) displaced persons. Hence, we argue that if scholars have a better understanding of the development of migration aspirations within a particular context, they will also be more able to understand related migration patterns and dynamics. Moreover, this focus contributes to the field of environmental sociology as it helps to better understand how people respond to their changing living environment, perceive it and opportunities therein, and adapt their aspirations to the perceived ability to deal with their environment (Dunlap and Marshall 2007; Gross and Heinrichs 2010). In doing so, this study aims to enable future researchers to better map out the vulnerabilities of people facing environmental changes and to contextualize their actions (Zickgraf 2018; Bose, 2016; Büscher and Davidov 2016).

Second, using the methodological approach to study environmental migration yields some interesting results and insights for future research. This research design seems to particularly novel due to the inclusion of immobile groups ('trapped populations', Zickgraf 2018) by focusing mainly on migrant aspirations and contrasting these against the migration trajectories when studying environmental 
migration. By including those groups unable to migrate, it also becomes clear that the constraints they perceive, complicate even the possibility to think of migrating themselves. Rather, migration aspirations are channelled through their wishes for their children. The latter is an interesting finding when developing questionnaires and interview topic lists to gauge people's migration aspirations (cf. EUMAGINE project, Timmerman et al. 2010, 2014a, b; Van Mol et al. 2018). The inclusion of these groups in the research sample was the most difficult part of the data collection, especially as this mainly involves the most vulnerable groups in society who are also the least alike the profiles of the researchers themselves. A second novelty of the applied methodological design for the study of environmental migration concerns the focus on two case studies in Morocco, which helps compare how different contexts perceive and are affected differently by environmental change - as well as many other societal factors - and how all these factors and ongoing changes interplay. Both regions attract different profiles of migrants, who are in some cases also searching for better opportunities elsewhere. Nevertheless, internal migrants and people considering migration in the future are not that easy to find and this almost always resulted from the interviews. Thus, the selection criteria, involving a diverse group of people with diverse migration trajectories and aspirations, often had to follow from the diversification of other sociodemographic background characteristics in the sample. The shift by the researcher in Morocco to focus on elderly females for the study of immobile groups was initially a lucky shot that led to fruitful results in terms of including new voices and perspectives in the research sample. This took considerable effort due to the gendered task divisions and social spheres in which men and women find themselves in the Moroccan context and their participation in 'outside' public life. These insights and experiences could be included and systematically studied in future research. Another difficulty of the research sample included in this book relates to the selection of the research population in terms of migrant trajectories and exact regions of origin, in both Belgium and Morocco. Linking migrant trajectories in regions of origin and destination together turned out to be more complicated than expected and hard to query during a first contact moment. Future research could also incorporate non-Moroccans (e.g., sub-Saharan African migrants) living in Morocco in the research sample as Morocco has become a key transit/destination country, especially in light of the fact that many (fragmented) migration journeys of sub-Saharan African migrants are often shaped by environmental factors (Lahlou 2015).

Third, as became clear from this book, the regional impact of environmental changes, as well as the local and historical migration dynamics matter for the ways in which environmental changes relate to migration aspirations and dynamics; and additionally, how this could lead to further maladaptation to the environmental changes or the development of better adaptation strategies to deal with environmental changes within this particular region. More regional case studies are needed for a better comparative study on how regional migration dynamics interfere with environmental changes and vice versa. With regard to the Moroccan case, the specific geographical, social, and political situation of distinct regions make their comparison very valuable. For instance, there has recently been more political turmoil in the 
northern region, near Oujda (Lahlou 2015), more economic investment in Tangier such as Med Port (El Imrani and Babounia 2016), an increase of environmental policy strategies in the southern part of Morocco, notably Plan Maroc Vert (El Bilali et al. 2012), making the comparison of these regions highly valuable.

Fourth, across and within countries, it would be interesting to examine the extent of the relationship between migration and environmental change, depending on the nature of the environmental changes (e.g., abrupt/gradual, floods/drought/heavy snowfall/sea level rise, etc.; cf. Bates 2002). Such environmental changes could be the trigger of continuous migration flows to nearby or distant destinations. At the same time, existing migration dynamics could be an incentive to increasingly aspire to migrate, especially when living in a deteriorating natural environment. As shown by the results of this book, which mainly considered gradual environmental change in Morocco, these environmental changes take more time and therefore interact to a high extent with other ongoing societal changes and rely on existing social structures. While these general conclusions may not differ that much from the case study by McLeman et al. (2016) on Hurricane Katrina, in which people are confronted with sudden weather shocks, the ways in environmental changes and their consequences affect people's everyday lives, societal structures, and communities differs.

A fifth point, that also adds to the previous one, relates to the need of future research to explicitly include the ways in which social, ethnic, and gender inequalities are strengthened or created through environmental change. This is necessary since vulnerabilities towards environmental changes vary across gender, socioeconomic status, profession, education level, and regions. Although often referred to in general in existing literature, the investigation of how existing inequalities are further reproduced and put under increased pressure due to environmental stressors is still in its infancy (McLeman et al. 2016). Especially with regard to gender, this research indicates that more in-depth analyses are needed to fully understand the development of migration aspirations due to environmental change. Previous research already found that gender is entangled with effects of disasters (e.g., McLeman et al. 2016), matters for decision-making during (environmental) migration (Obokata et al. 2014; Van Mol et al. 2018; De Jong 2000; Boyd and Grieco 2003), and leads to different vulnerabilities, sensitivities (Chindarkar 2012) and adaptive capacities to environmental/climate change (Masika 2002). Furthermore, gender does not only matter for the active undertaking of migration trajectories, but also for those who do not manage to migrate (Boyd and Grieco 2003) as well as for migration aspirations (Masika 2002; Chindarkar 2012; Gioli and Milan 2018). This book's findings already suggest that gender relations and its importance for understanding environmental migration and the development of migration aspirations should be studied within the local economic context and over time. More specifically, gender roles and gendered divisions of tasks with regard to land use matter when examining the vulnerabilities of people confronted with environmental change as well as their ability to migrate. More gender-sensitive analyses are, however, needed to disentangle gender, migration aspirations, and environmental change.

Sixth, building further on one of the previous methodological remarks, efforts should be made to focus on immobile groups, which in the Moroccan context are 
often identified as elderly females and poorer, vulnerable groups. Since it seems hard to imagine and aspire to migrate when you are aware of your social and financial constraints, future research should apply an intergenerational family approach to the study of (environmental) migrant aspirations. By focusing on different generations, greater insight can be derived in how migration aspirations can be passed through generations and the motivations behind such parental aspirations (e.g., in terms of the household family income or applied adaptation strategies to deal with environmental change).

Seventh, more research should consider the views on nature and the relationship with humans when discussing all aspects related to environmental changes. The strategies people develop when dealing with environmental changes are shaped by such views. Climate change discourses seem to be insufficiently applied to people's immediate living environment and therefore people do not seem to link these discourses to their own situation. Hence, knowledge on climate change discourses does not necessarily result in the development of strategies to adapt to environmental change. These discourses need to be injected with tacit knowledge and skills from people living in gradually-degrading living environments and, for instance, working in agriculture or in fields more heavily affected by environmental change. Interestingly, these views and this type of knowledge and skills are hardly considered in policies concerning environmental changes (e.g. Bremer et al. 2017; IPCC 2014). This would add to a better understanding of the importance of the social, cultural, and religious context, as well as the importance of the specificity of the environmental changes for the development of climate change discourses and perceptions concerning environmental changes, their impact, and how to adapt to them. These studies could draw inspiration from fields of study such as sociology of risk, disaster studies, and so on.

Furthermore, more in-depth research should be done regarding the references that respondents make to the content of local religious and cultural beliefs concerning this topic. When looking at the importance of religion while discussing these views on environmental change and the role of people herein in the Moroccan context, the multidimensionality of religion needs to be assessed as well (Glock and Stark 1965; Cornwall et al. 1986; Hill and Hood 1999). More research is needed on how personal and institutional dimensions of religiosity impact people's vulnerabilities, resilience, and views on environmental change, and how this impacts the development of (additional) adaptation strategies for dealing with environmental changes in their immediate environment. These dimensions of religiosity could refer to beliefs, behaviours, and commitment at both the institutional and personal levels (Cornwall et al. 1986). Consequently, religiosity could be related to environmental change in many ways. When being applied to Islam, the most common religion in the Moroccan context, there are many verses in the Quran explaining that mankind should take care of the environment, protect it against climate change, and prevent overconsumption of its resources. Although already in 2015 the Islamic Climate Change Symposium had adopted the Islamic Declaration on Global Climate Change, hardly any attention was given to religious, Islamic views on nature protection in other policies to reduce climate change (e.g, IPCC reports), nor did scholars include 
Islamic views on climate change in their studies. Finally, in the Moroccan context, it would be interesting to examine in a more systematic way how this varies across Arab and Amazigh cultures and regions within Morocco (cf. Chaps. 3 and 5).

Eighth, future studies could systematically map out the effective remittance flows between migrant networks and their regions of origin to explicitly study how these remittances are on a large scale used to deal with environmental changes or not. Remittances could also have a very negative effect on the region of origin due to the lack of investment in adaptation strategies to deal with environmental changes and the disconnection between the educational and professional aspirations of people living in a particular region from the economic and social conditions as well as opportunities in that region. As shown from our results, migration could be used as an individual adaptation strategy to deal with environmental change. Nevertheless, when making migration work for a larger community or society, more coordinated action is necessary, and evaluation research on these actions is highly needed. By systematically evaluating adaptation strategies used to cope with the effects of environmental change, all aspects related to migration are incorporated and a better overview of the combined advantages and disadvantages could be provided. It is important here is to study the combined effect of different adaptation strategies together.

A ninth future research recommendation is to connect the accounts of potential migrants in a network approach with their migrant relatives in order to map the information streams and analyse the importance of social capital for the development and applications of climate change discourses (Smith et al. 2012) as well as the sending of remittances and other resources. Furthermore, additional research is needed to study how the importance of these networks varies by comparing different settings, contexts, countries (cf. Bryan et al. 2009), and continents.

\subsection{Conclusions}

The distinct chapters of this book highlight how environmental changes and migration dynamics interplay within the Moroccan context, and more specifically in Tangier and Tinghir, as well as for people of the Moroccan diaspora in Belgium. This comparative and complementary case study approach focuses mainly on how environmental changes are felt through the existing social structures - gender relations in families and society, distinct socio-economic vulnerabilities and resilience in society related to educational level, professions and dependence on the natural living environment, and the added advantages of having access to all kinds of remittances from migrant networks. The use of this regional approach helps to examine how societal structures are crucial for a better understanding of the potential migration dynamics triggered by environmental changes. More importantly, the book's findings demonstrate how the existing migration networks - in some cases - impact how local governments and inhabitants deal with, and adapt to, the changing natural (and social) living environment. The mutual influences of both 
migration and environmental factors is often insufficiently considered in previous theories on environmental migration (cf. 'migration-as-adaptation discourse', Gemenne 2010; Gemenne and Blocher 2016) and when developing theoretical frameworks that attempt to grasp the determinants of environmental migration (cf. the Foresight report, TGOFS 2011). By building further on existing insights in migration theories and applying them to the study of environmental migration within Morocco and from Morocco to Belgium, this book aims to demonstrate how regional specifications of local dynamics and structures as well as transnational migrant networks and systems need to be studied together in order to understand environmental migration and displacement. These local structures and migrant networks are part of the adaptive capacity of individuals and regions in general.

\section{References}

Adam, B. (1998). Timescapes of modernity. The environment and invisible hazards. London: Routledge.

Adam, B. (2005). Futures in the making: Contemporary practices and sociological challenges. American Sociological Association Annual Meeting, Philadelphia, 13-16 August. http://www. cf.ac.uk/socsci/futures/conf_ba_asa230905.pdf

Adger, W. N., Dessai, S., Goulden, M., Hulme, M., Lorenzoni, I., \& Nelson, D. R. (2009). Are there social limits to adaptation to climate change? Climatic Change, 93(3-4), 335-354.

Ammar, N. H. (2013). An Islamic response to the manifest ecological crisis: Issues of justice. In R. Gottlieb (Ed.), This sacred earth: Religion, nature, environment (2nd ed.). London: Routledge.

AU. (2009). African Union Convention for the Protection and Assistance of Internally Displaced Persons in Africa (Kampala Convention). https://au.int/en/treaties/african-union-conventionprotection-and-assistance-internally-displaced-persons-africa

Bates, D. C. (2002). Environmental refugees? Classifying human migrations caused by environmental change. Population and Environment, 23(5), 465-477. www.jstor.org/stable/27503806.

Beck, U. (1992). Risk society. Towards a new modernity. London: Sage.

Biermann, F., \& Boas, I. (2008). Protecting climate refugees: The case for a global protocol. Environment Science and Policy for Sustainable Development, 50(6), 8-17. https://doi.org/10. 3200/ENVT.50.6.8-17.

Biermann, F., \& Boas, I. (2017). Towards a global governance system to protect climate migrants: Taking stock. In B. Mayer, F. Crépeau, \& G. Cheltenham (Eds.), Research handbook on climate change, migration and the law (Research Handbooks in Clima Law series) (pp. 405-419). Cheltenham: Edward Elgar Publishing Ltd..

Biesbroek, G. R., Klostermann, J. E., Termeer, C. J., \& Kabat, P. (2013). On the nature of barriers to climate change adaptation. Regional Environmental Change, 13(5), 1119-1129.

Bose, P. (2016). Vulnerabilities and displacements: Adaptation and mitigation to climate change as a new development mantra. Area, 48(2), 168-175. https://doi.org/10.1111/area.2016.48.issue-2.

Boyd, M., \& Grieco, E. (2003). Women and migration: Incorporating gender into international migration theory. Migration Policy Institute, retrieved from https://www.migrationpolicy.org/ article/women-and-migration-incorporating-gender-international-migration-theory

Bremer, S., Blanchard, A., Mamnun, N., Stiller-Reeve, M., Haque, M. M., \& Tvinnereim, E. (2017). Narrative as a method for eliciting tacit knowledge of climate variability in Bangladesh. Weather, Climate, and Society, 9(4), 669-686.

Bryan, E., Deressa, T. T., Gbetibuou, T. A., \& Ringler, C. (2009). Adaptation to climate change in Ethiopia and South Africa: Options and constraints. Environmental Science and Policy, 12, 413-426. 
Burck, J., Marten, F., Höhne, N., \& Bals, C. (2019). The climate change performance index: Results 2019. Berlin: Germanwatch.

Büscher, B., \& Davidov, V. (2016). Environmentally induced displacements in the ecotourismextraction Nexus. Area, 48(2), 161-167. https://doi.org/10.1111/area.2016.48.issue-2.

Carling, J., \& Schewel, K. (2018). Revisiting aspiration and ability in international migration. Journal of Ethnic and Migration Studies, 44(6), 945-963.

Chindarkar, N. (2012). Gender and climate change-induced migration: Proposing a framework for analysis. Environmental Research Letters, 7(2), 025601.

Collyer, M. (2010). Stranded migrants and the fragmented journey. Journal of Refugee Studies, 23 (3), 273-293. https://doi.org/10.1093/jrs/feq026.

Cornwall, M., Albrecht, S. L., Cunningham, P. H., \& Pitcher, B. L. (1986). The dimensions of religiosity: A conceptual model with an empirical test. Review of Religious Research, 27, 226-244.

Crawley, H., \& Skleparis, D. (2017). Refugees, migrants, neither, both: Categorical fetishism and the politics of bounding in Europe's 'migration crisis'. Journal of Ethnic and Migration Studies, 44(1), 48-64. https://doi.org/10.1080/1369183X.2017.1348224.

Czaika, M. \& De Haas, H. (2011). The effectiveness of immigration policies. A conceptual review of empirical evidence. IMI Working Papers Series. DEMIG project paper no. 3.

De Haas, H. (2003). Migration and development in southern Morocco. The Disparate SocioEconomic Impacts of Out-Migration on the Todgha Oasis Valley. Doctoral dissertation, Katholieke Universiteit Nijmegen, Nijmegen.

De Haas, H. (2006). Migration, remittances and regional development in Southern Morocco. Geoforum, 37(4), 565-580. https://doi.org/10.1016/j.geoforum.2005.11.007.

De Haas, H. (2007). Morocco's migration experience: A transitional perspective. International Migration, 45(4), 39-70. https://doi.org/10.1111/j.1468-2435.2007.00419.x.

De Haas, H. (2010). The internal dynamics of migration processes: A theoretical inquiry. Journal of Ethnic and Migration Studies, 36(10), 1587-1617. https://doi.org/10.1080/1369183X.2010. 489361.

De Haas, H., \& El Ghanjou, H. (2000). General Introduction to the Todgha Valley population, migration, agricultural development (IMAROM Working Paper Series no. 5). Amsterdam: University of Amsterdam.

De Jong, G. F. (2000). Expectations, gender, and norms in migration decision-making. Population Studies, 54(3), 307-319.

Dunlap, R.E., Marshall, B.K. (2007). Environmental sociology. 21st Century Sociology. Volume 2, 329-340, Thoasand Oaks: Sage.

Eckstein, S. (2010). Immigration, remittances, and transnational social capital formation: A Cuban case study. Ethnic and Racial Studies, 33(9), 1648-1667. https://doi.org/10.1080/ 01419871003725410.

El Bilali, H., Berjan, S., Driouetch, N., Ahouate, L., Abouabdill, A., Najid, A., \& Azim, K. (2012). Agricultural and rural development governance in Morocco. Paper presented at the third international scientific symposium 'Agrosym 2012', Jahorina, Bosnia and Herzegovina, 15-17 November. Book of Proceedings.

El Imrani, O., \& Babounia, A. (2016). Tangier med port: What role for the Moroccan economy and the international trade? International Journal of Research in Management, Economics and Commerce, 6(7), 73-81.

Farbotko, C., \& Lazrus, H. (2012). The first climate refugees? Contesting global narratives of climate change in Tuvalu. Global Environmental Change, 22(2), 382-390.

Gemenne, F. (2010). Migration, a possible adaptation strategy? Institut du développement durable et des relations internationales, $3,1-4$.

Gemenne, F., \& Blocher, J. (2016). How can migration support adaptation? Different options to test the migration-adaptation nexus. Migration, Environment and Climate Change. Working paper IOM. https://doi.org/10.13140/RG.2.1.2010.6008.

Gioli, G., \& Milan, A. (2018). Gender, migration and (global) environmental change. In R. McLeman \& F. Gemenne (Eds.), Routledge handbook of environmental displacement and migration. London/New York: Routledge. 
Glock, C. Y., \& Stark, R. (1965). Religion and society in tension. Chicago: Rand McNally.

Gross, M., \& Heinrichs, H. (Eds.). (2010). Environmental sociology: European perspectives and interdisciplinary challenges. Springer Science \& Business Media.

Haenn, N., \& Wilk, R. R. (2006). The environment in anthropology. In A reader in ecology, culture, and sustainable living. New York/London: New York University Press.

Hart, D. (1999). Scratch a Moroccan, find a Berber. The Journal of North African Studies, 4(2), 23-26. https://doi.org/10.1080/13629389908718359.

Havard, B. (2007). Seeking protection: Recognition of environmentally displaced persons under international human rights law. Villanova Environmental Law Journal, 18(1), 64-82.

Hill, P. C., \& Hood, R. W., Jr. (1999). Measures of religiosity. Birmingham: Religious Education Press.

Intergovernmental Panel on Climate Change (IPCC). (2014). Climate Change 2014: Synthesis Report. Contribution of Working Groups I, II and III to the Fifth Assessment Report of the Intergovernmental Panel on Climate Change [Core Writing Team, R.K. Pachauri and L.A. Meyer (eds.)]. Geneva: IPCC.

Izzy Deen, M. Y. (2003). Islamic environmental ethics, law and society. In R. Gottlieb (Ed.), This Sacred Earth: Religion, Nature, Environment (2nd ed.). London: Routledge.

Karrouche, N. F. F. (2017). National Narratives and the invention of ethnic identities: Revisiting cultural memory and the decolonized state in Morocco. In Palgrave Handbook of Research in Historical Culture and Education (pp. 295-310). London: Palgrave MacMillan.

Khachani, M. (2009). The impact of migration on the Moroccan economy. Journal of Ethnic and Migration Studies, 35(10), 1609-1621. https://doi.org/10.1080/13691830903165832.

Lahlou, M. (2015). Morocco's experience of migration as a sending, transit and receiving country. Istituto Affari Internazionali, Working Paper No. 15:1-19, http://www.iai.it/sites/default/files/ iaiwp1530.pdf. Accessed 7 Aug 2019,

Lobell, D. B., Baldos, U. L. C., \& Hertel, T. W. (2013). Climate adaptation as mitigation: The case of agricultural investments. Environmental Research Letters, 8(1), 1-12. https://doi.org/10. 1088/1748-9326/8/1/015012.

Masika, R. (2002). Gender, development, and climate change. Oxford: Oxfam.

McLeman, R., \& Gemenne, F. (2018). Environmental migration research. Evolution and current state of the science. In R. McLeman \& F. Gemenne (Eds.), Routledge handbook of environmental displacement and migration (pp. 3-16). London/New York: Routledge.

McLeman, R., Schade, J., \& Faist, T. (2016). Environmental migration and social inequality. In Advances in Global change Research (Advances in Global Change Research, 61). Geneva: Springer.

McNamara, K. E., \& Gibson, C. (2009). We do not want to leave our land': Pacific ambassadors at the United Nations resist the category of 'climate refugees. Geoforum, 40, 475-483.

Morel, M., \& de Moor, N. (2012). Migrations climatiques: quel rôle pour le droit international? Cultures and Conflicts, 88, 61-84.

Nyberg Sørensen, N. (2004). Migrant remittances as a development tool: The case of Morocco. Copenhagen: Danish Institute for Development Studies.

Obokata, R., Veronis, L., \& McLeman, R. (2014). Empirical research on international environmental migration: A systematic review. Population and Environment, 36(1), 111-135.

Portes, A., Guarnizo, L. E., \& Haller, W. J. (2002). Transnational entrepreneurs: An alternative form of immigrant economic adaptation. American Sociological Review, 67(2), 278-298. https://doi.org/10.2307/3088896.

Rigby, K. (2016). Religion and ecology: Towards a communion of creatures. In S. Oppermann \& S. Iovino (Eds.), Environmental humanities: Voices from the Anthropocene (pp. 273-294). London: Rowman and Littlefield.

Salmón, E. (2000). Kincentric ecology: Indigenous perceptions of the human-nature relationship. Ecological Applications, 10(5), 1327-1332. 
Schilling, J., Freier, K. P., Hertig, E., \& Scheffran, J. (2012). Climate change, vulnerability and adaptation in North Africa with focus on Morocco. Agriculture, Ecosystems Environment, 156, $12-26$.

Smith, J. W., Anderson, D. H., \& Moore, R. L. (2012). Social capital, place meanings, and perceived resilience to climate change. Rural Sociology, 77(3), 380-407. https://doi.org/10. 1111/j.1549-0831.2012.00082.x.

Stavropoulou, M. (2008). Drowned in definitions? Climate change and displacement. Forced Migration Review, 31, 11-12.

The Government Office for Science (TGOFS). (2011). Foresight: Migration and global environmental change future challenges and opportunities. London: The Government Office for Science.

Timmerman, C., Heyse, P., \& Van Mol, C. (2010). Project paper 1: Conceptual and theoretical framework. EUMAGINE Research Project. Antwerp: University of Antwerp.

Timmerman, C., De Clerck, H. M.-L., Hemmerechts, K., \& Willems, R. (2014a). Imagining Europe from the outside: The role of perceptions of human rights in Europe in migration aspirations in Turkey, Morocco, Senegal and Ukraine. In N. Chaban \& N. Holland (Eds.), Communicating Europe in times of crisis external perceptions of the European Union (pp. 220-247). Basingstoke: Palgrave Macmillan.

Timmerman, C., Hemmerechts, K., \& De Clerck, H. M.-L. (2014b). The relevance of a 'culture of migration' in understanding migration aspirations in contemporary Turkey. Turkish Studies, 15 (3), 496-518. https://doi.org/10.1080/14683849.2014.95474.

UN. (2018). https://www.un.org/press/en/2018/ga12113.doc.htm

UNDP. (2018). Climate Change Adaptation [online]. https://adaptation-undp.org. Accessed 7 Jan 2018.

UNHCR. (2018). Internally Displaced People [online]. https://www.unhcr.org/en-us/internallydisplaced-people.html. Accessed 7 Jan 2018.

Van Mol, C., Snel, E., Hemmerechts, K., \& Timmerman, C. (2018). Migration aspirations and migration cultures: A case study of Ukrainian migration towards the European Union. Population, Space and Place, 24(5), 21-31. https://doi.org/10.1002/psp.2131.

Wodon, Q., \& Liverani, A. (2014). Climate change, migration, adaptation in the MENA region. In Q. Wodon, A. Liverani, G. Joseph, \& N. Bougnoux (Eds.), Climate change and migration. Evidence from the Middle East and North Africa (pp. 3-36). Washington, DC: The World Bank.

Zetter, R. (2017). Why they are not refugees - Climate change, environmental degradation and population displacement. Turku: Migration Institute of Finland.

Zickgraf, C. (2018). Immobility. In R. McLeman \& F. Gemenne (Eds.), Routledge handbook of environmental displacement and migration (pp. 71-84). London/New York: Routledge.

Open Access This chapter is licensed under the terms of the Creative Commons Attribution 4.0 International License (http://creativecommons.org/licenses/by/4.0/), which permits use, sharing, adaptation, distribution and reproduction in any medium or format, as long as you give appropriate credit to the original author(s) and the source, provide a link to the Creative Commons license and indicate if changes were made.

The images or other third party material in this chapter are included in the chapter's Creative Commons license, unless indicated otherwise in a credit line to the material. If material is not included in the chapter's Creative Commons license and your intended use is not permitted by statutory regulation or exceeds the permitted use, you will need to obtain permission directly from the copyright holder.

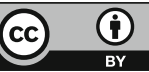

